\title{
In Vitro Study of Neutrophil Apoptosis in Liver Cirrhosis
}

\author{
Nobuhide Kusaba, Ryukichi Kumashiro, Hideaki Ogata, Michio Sata and Kyuichi TaniKawa
}

\begin{abstract}
Cirrhotic patients frequently manifest neutropenia and are predisposed to bacterial infections. We examined neutrophil apoptosis to determine if neutrophil survival in cirrhotic patients is shortened. Neutrophils isolated from 10 cirrhotic patients and 10 healthy volunteers were cultured for 24 hours. The time course of neutrophil viability was assessed by the trypan blue dye exclusion test and apoptosis was determined morphologically by light and electron microscopy. Apoptotic cells were also confirmed by terminal deoxynucleotidyl transferase-mediated deoxyuridine triphosphate nick and labeling (TUNEL) and DNA gel electrophoresis. Fas expression of neutrophils was examined by flow cytometry. Viabilities were significantly decreased in liver cirrhosis $(\mathbf{p}<0.0001)$. Neutrophils from cirrhotic patients exhibited significantly greater apoptosis. Fas expression of neutrophils was significantly reduced for cirrhotic patients $(\mathrm{p}=\mathbf{0 . 0 0 0 1})$. Neutrophils from cirrhotic patients exhibited markedly accelerated apoptosis in vitro. Shortening of neutrophil survival via apoptosis may explain in part the mechanism of neutropenia in cirrhotic patients.

(Internal Medicine 37: 11-17, 1998)
\end{abstract}

Key words: cell death, leukopenia, Fas, DNA analysis, terminal deoxynucleotidyl transferasemediated deoxyuridine triphosphate nick and labeling (TUNEL)

\section{Introduction}

Cirrhotic patients frequently exhibit anemia, leukopenia, and thrombocytopenia. Several mechanisms underlying anemia such as folate deficiency, hypersplenism and hemolysis, such as in spur cell anemia, have been described (1-3). Hypersplenism and shorter life span of thrombocytes have been shown to cause thrombocytopenia $(2,4,5)$. In the pathogenesis of neutropenia, splenomegaly and serum hematopoietic progenitor cell inhibitory factors have been reported (6-9). However, an accurate kinetic study of neutrophils is difficult to perform because the halflife of a neutrophil may be less than 7 hours (10) in healthy subjects.

Recently, apoptosis has been acknowledged as a physiological suicide mechanism and many cell types undergo programmed death via apoptosis to maintain homeostasis (11). The apoptosis of neutrophils in vitro was first reported by Savill et al (12). Grigg et al observed many apoptotic neutrophils phagocytosed by alveolar macrophages (13). The liver and the spleen were also shown to be important organs for the disposal of apoptotic neutrophils, as reported by Shi et al (14). We assumed that accelerated neutrophil apoptosis led to shortening of neutrophil survival and may be partly involved in neutropenia in cirrhotic patients. To clarify the issue described above, we cultured neutrophils and compared the frequency of neutrophil apoptosis in cirrhotic patients and controls.

\section{Methods}

\section{Subjects}

Healthy volunteers $(n=10)$ and cirrhotic patients with a neutrophil count of less than $2,000 / \mathrm{mm}^{3}(\mathrm{n}=10)$ were enrolled. The diagnosis of liver cirrhosis was based on clinical and laboratory findings, including liver biopsy. Patients with cirrhosis complicated by hepatocellular carcinoma of less than $2 \mathrm{~cm}$ in diameter were included. Patients with fever, positive Creactive protein, or who were under treatment were excluded. The cirrhotic patient group included 3 men and 7 women (4275 years of age). Control subjects included 6 men and 4 women (35-80 years of age). The cause of liver cirrhosis was hepatitis $\mathrm{C}$ virus in 8 patients and hepatitis B virus in 2 patients. Informed consent was obtained from every patient and the study was approved by the ethics committee of Kurume University.

\section{Neutrophil isolation and culture}

Heparinized blood samples from a peripheral vein were mixed with an equal volume of phosphate-buffered saline (PBS, pH 7.4). Leukocytes were separated from erythrocytes

From the Second Department of Medicine, Kurume University School of Medicine, Kurume

Received for publication April 9, 1997; Accepted for publication October 3, 1997

Reprint requests should be addressed to Dr. Nobuhide Kusaba, the Second Department of Medicine, Kurume University School of Medicine, 67 Asahi-machi, Kurume, Fukuoka 830 
by dextran sedimentation using $0.6 \%$ dextran (Wako Pure Chemical Industries, Osaka) for 30 minutes. The leukocyterich upper layer was fractionated using a modification of the discontinuous plasma-percoll (Pharmacia Fine Chemicals, Uppsala, Sweden) gradient technique described by Haslett et al (15). After centrifugation at $200 \mathrm{~g}$ for 30 minutes at room temperature, neutrophils were collected at the interface, washed twice in PBS, and resuspended at a concentration of $5.0 \times 10^{6} / \mathrm{ml}$ in RPMI 1640 (Nissui Pharmaceutical Co., Ltd., Tokyo). The medium was supplemented with $10 \%$ fetal bovine serum (GIBCO BRL, Grand Island, N.Y.), $0.2 \mathrm{mM}$ L-glutamine (Nissui), $25 \mathrm{U} / \mathrm{ml}$ penicillin (Meiji, Tokyo), and $25 \mathrm{mg} / \mathrm{ml}$ streptomycin (Meiji). The neutrophils were $\geqq 95 \%$ pure by May-Giemsa staining and $\geqq 98 \%$ viable by trypan blue dye exclusion. The cell suspensions were seeded into 6-well flatbottom plates (Falcon 3046, Becton Dickinson and Company, Lincolon Park, New Jersey) and cultured at $37^{\circ} \mathrm{C}$ in $5 \% \mathrm{CO}_{2}$ for 24 hours.

\section{Neutrophil viability}

At each designated time, neutrophil viability was assessed by trypan blue dye exclusion. One vol of $0.4 \%$ trypan blue was added to $5 \mathrm{vol}$ of cell suspension. After incubation at room temperature for 5 minutes, cells were counted in a hemocytometer. All counts were performed in triplicate with coded samples.

\section{Light microscopy}

Cytospins were prepared using a Shandon Cytospin 2 (Shandon Inc., Pittsburg, PA) and stained with May-Giemsa stain. A total of 500 cells were counted by light microscopy at a high magnification $(1,000 \times)$. Apoptotic cells were identified according to the following criteria of Savill et al (12): condensed or fragmented nuclei, cytoplasmic vacuolation, and decrease in cell size.

\section{Transmission electron microscopy}

Neutrophils cultured after 24 hours were fixed in $1 \%$ glutaraldehyde in $0.05 \mathrm{M}$ cacodylate buffer and $7.5 \%$ sucrose in 0.05 $\mathrm{M}$ cacodylate buffer for 3 hours. The samples were postfixed with $1 \%$ osmium tetroxide for 1 hour, dehydrated, and embedded in epoxy resin (Nissin EM, Tokyo). Thin sections were cut, double contrast-labeled with uranyl acetate and lead citrate, and examined with an electron microscope (H-7,000, Hitachi) at 75 $\mathrm{kV}$.

Terminal deoxynucleotidyl transferase-mediated deoxyuridine triphosphate nick and labeling (TUNEL) assay

The TUNEL assay (16) was employed to observe DNA fragmentation in neutrophils. After 12 hours of culture, neutrophils were collected on poly-l-lysine-coated glass slides (Sigma, Chemical Co., St Louis, MO) using cytospin. The samples were fixed with $4 \%$ fresh formaldehyde solution in PBS. After washing twice with PBS, the samples were permeabilized in Triton X (Wako) solution in PBS. After being washed with PBS, the fragmented DNA of neutrophils were labeled with fluorescein-12-dUTP using an Apoptosis Detection System, Fluorescein (Promega Corporation, Madison, WI) according to the manufacturer's protocol. Subsequently, the samples were counterstained with propidium iodide $(1 \mu \mathrm{g} / \mathrm{ml}$; Sigma), and analyzed by confocal laser microscopy (Olympus LSM-GB 200, Tokyo).

\section{DNA electrophoresis}

Neutrophils $\left(5.0 \times 10^{6}\right.$ cells $)$ were removed from culture after 12 hours and 24 hours, collected into Eppendorf tubes, and washed twice with cold PBS. The samples were resuspended in $400 \mu \mathrm{l}$ DNA extraction buffer (10 mM Tris $\mathrm{HCl} \mathrm{PH}$ 8.0, 150 $\mathrm{mM} \mathrm{NaCl}, 10 \mathrm{mM}$ ethylenediaminetetraacetic acid (EDTA), and $2 \%$ SDS $)$. Proteinase K $(500 \mu \mathrm{g} / \mathrm{ml}$; Boehringer Mannheim $\mathrm{GmbH}$, Mannheim, Germany) and RNase (20 $\mu \mathrm{g} / \mathrm{ml}$; Sigma) were added, and these suspensions were incubated for 18 hours at $37^{\circ} \mathrm{C}$. DNA was extracted twice by means of phenol-chloroform, then precipitated with $0.1 \mathrm{vol}$ of $3 \mathrm{M}$ sodium acetate (Nippon Gene Co., Tokyo) and 2.5 vol of $100 \%$ cold ethanol, and stored for 1 hour at $-70^{\circ} \mathrm{C}$. The precipitates were rinsed with $70 \%$ ethanol and dried. DNA-pellets were resuspended in TE buffer (10 mM Tris HCl, $1 \mathrm{mM}$ EDTA PH 8.0) and heated for 10 minutes at $70^{\circ} \mathrm{C}$. DNA $(10 \mu \mathrm{g})$ was applied to each lane on $1 \%$ agarose gel containing $1.0 \mu \mathrm{g} / \mathrm{ml}$ ethidium bromide (Nippon Gene). The electrophoresis was performed for 220 minutes at $50 \mathrm{~V}$, and the gel was photographed under UV light. The size of DNA fragments in the samples was compared with a standard ladder (GIBCO).

\section{Expression of Fas antigen}

All incubations were performed using PBS containing 1\% bovine serum albumin (Wako) and $0.1 \%$ sodium azide (binding buffer). Fresh isolated neutrophils were washed at $4^{\circ} \mathrm{C}$ in binding buffer and suspended $\left(5 \times 10^{5}\right)$ in $50 \mu$ l binding buffer. The cells were incubated with FITC-conjugated anti-Fas monoclonal antibody (clone UB-2; MBL, Nagoya) or an isotypematched FITC-conjugated mouse IgG1 mAb (Becton Dickinson, Mountain View, CA) for 15 minutes at room temperature. The cells were washed twice with binding buffer at $4^{\circ} \mathrm{C}$ and fixed with $1 \%$ paraformaldehyde in PBS. The stained cells were immediately analyzed on a Cytron Absolute flow cytometer (Ortho Diagnostic systems, Tokyo).

\section{Statistical analysis}

Results are expressed as the mean \pm standard deviation. To assess survival and apoptosis rates, the repeated measure ANOVA was used. Fas antigen expression data were analyzed by Mann-Whitney's U test. Statistical significance was defined as $\mathrm{p}<0.05$.

\section{Results}

\section{Neutrophil viability in control and cirrhotic patients}

After percoll gradient centrifugation, neutrophil viabilities in both control and cirrhotic patients exceeded $98 \%$. Neutrophil viabilities in cirrhosis and controls were $96.3 \pm 2.2$ and $98.5 \pm$ 
$1.4 \%$ at 4 hours, $91.4 \pm 5.4$ and $97.1 \pm 1.8 \%$ at 8 hours, $79.6 \pm$ 5.8 and $89.3 \pm 4.5 \%$ at 12 hours, and $34.5 \pm 13.1$ and $53.5 \pm$ $12.6 \%$ at 24 hours, respectively (Fig. 1). There was a significant difference $(p<0.0001)$ in viability between cirrhotic patients and control subjects.

\section{The light microscopic evaluation of apoptosis}

Neutrophils exhibiting the morphological changes of apoptosis are demonstrated in Fig. 2A and B. In fresh isolated neutrophils from cirrhotic patients, $1.8 \%$ of neutrophils had

Figure 1. Time course for the viability of cultured neutrophils in control subjects and in liver cirrhosis. Cell viability was assessed by the trypan blue dye exclusion test. The results are expressed as mean \pm SD. Data were analyzed by repeated measure ANOVA. Neutrophil viabilities were significantly $(* p<0.0001)$ decreased for cirrhotic patients $(n=10)$ compared to control subjects $(n=10)$.
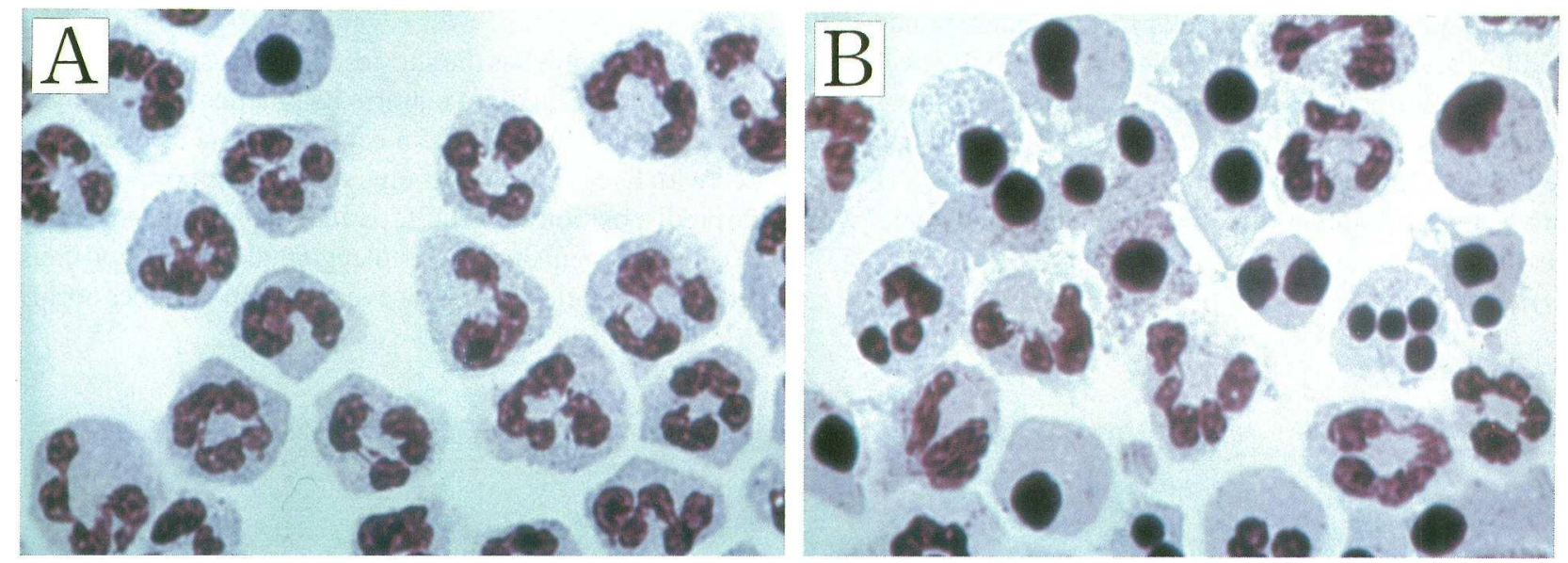

Figure 2. Morphological features of neutrophil apoptosis during culture. Light microscopic examination of neutrophils cultured for 8 hours $(\times 1,000)$. (A) Control neutrophils, and (B) neutrophils from a cirrhotic patient. Cells with highly condensed or fragmented nuclei and vacuolated cytoplasm were considered apoptotic. The number of apoptotic neutrophils was markedly greater in liver cirrhosis than in controls. (C) Time course for apoptosis of cultured neutrophils in control and liver cirrhosis. The results are expressed as mean \pm SD. Data were analyzed by repeated measure ANOVA. Apoptosis was significantly (*p<0.05) increased for neutrophils from cirrhotic patients $(n=10)$ compared to control neutrophils $(n=10)$. 
already exhibited morphological features of apoptosis (data not shown). The incidences of apoptotic neutrophils in cirrhotic patients and controls were $4.6 \pm 2.9$ and $1.5 \pm 1.4 \%$ at 4 hours, $40.9 \pm 20.6$ and $17.3 \pm 14.5 \%$ at 8 hours, $59.3 \pm 23.1$ and 37.4 $\pm 16.8 \%$ at 12 hours, and 24 hours $92.4 \pm 6.9$ and $78.9 \pm 15.8 \%$ at 24 hours, respectively (Fig. 2C). Statistical significance for control and cirrhotic patients was demonstrated at every time point in culture $(\mathrm{p}<0.05)$.

\section{Electron microscopic evaluation of apoptosis}

More than $90 \%$ of cirrhotic neutrophils cultured for 24 hours demonstrated condensed chromatin or formed crescents of chromatin, rounded nuclear profiles, cytoplasmic vacuolations, increase in the electron density of the cytoplasm, cell shrinkage, and loss of microvilli and pseudopodia. However, the plasma membrane and cellular organellas remained intact (Fig. 3). These cells are characteristic of apoptotic cells $(17,18)$.

\section{TUNEL assay}

Nuclei with fragmented DNA were labeled green with fluorescein-12-dUTP and the cells were counterstained with propidium iodide in red. TUNEL-positive cells appeared as intensively yellow fluorescent cells at confocal laser microscopy. A much larger population of neutrophils of cirrhotic patients were TUNEL-positive as compared to controls (Fig.4). TUNELpositive cells with intense fluorescence had round nuclei with no lobules.

\section{Electrophoretic analysis of DNA}

Figure 5 shows representative results of ten separate experiments. In cirrhotic patients, a ladder of DNA fragments of 180 $200 \mathrm{bp}$ was clearly exhibited. The ladder formation was more clearly observed in neutrophils from cirrhotic patients than in those from controls during the entire experimental period up to 24 hours.

\section{Expression of Fas antigen on neutrophils}

Expression of Fas antigen on neutrophils freshly isolated from control and cirrhotic patients was evaluated by flow cytometric analysis. Neutrophils from cirrhotic patients expressed significantly less Fas antigen than did those from controls ( $39.6 \pm 13.4$ vs. $75.7 \pm 17.6 \%, p=0.0001)$. Figure $6 B$ demonstrates the representative histograms. The histograms illustrate that neutrophils from controls have a markedly larger population with a high fluorescence intensity than did neutrophils from cirrhotic patients.

\section{Discussion}

The neutrophil has the shortest life span among white blood cells and it is difficult to confirm its kinetics in the body. So, it is not easy to elucidate the mechanism of neutropenia associated with liver cirrhosis. Its elucidation is important because of the predisposition of cirrhotic patients to bacterial infection (19, 20). Hypersplenism has been regarded as a major cause of neutropenia in cirrhosis. However, neutropenia does not always

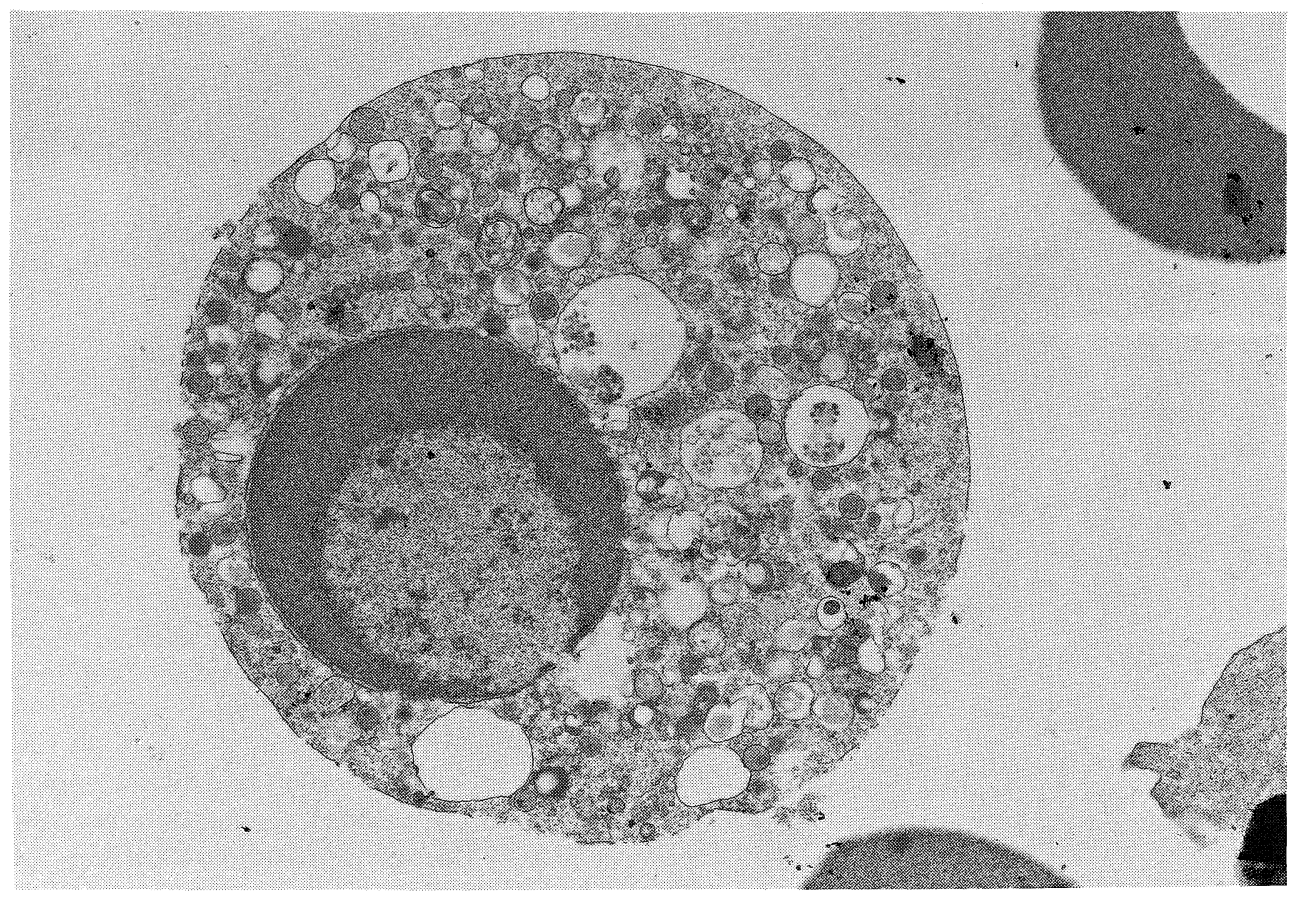

Figure 3. Electron microscopic observation of neutrophils cultured for 24 hours $(\times 5,000)$. A neutrophil shows condensed chromatin and the formation of crescents of chromatin while the cell membrane and organellas remain intact. 

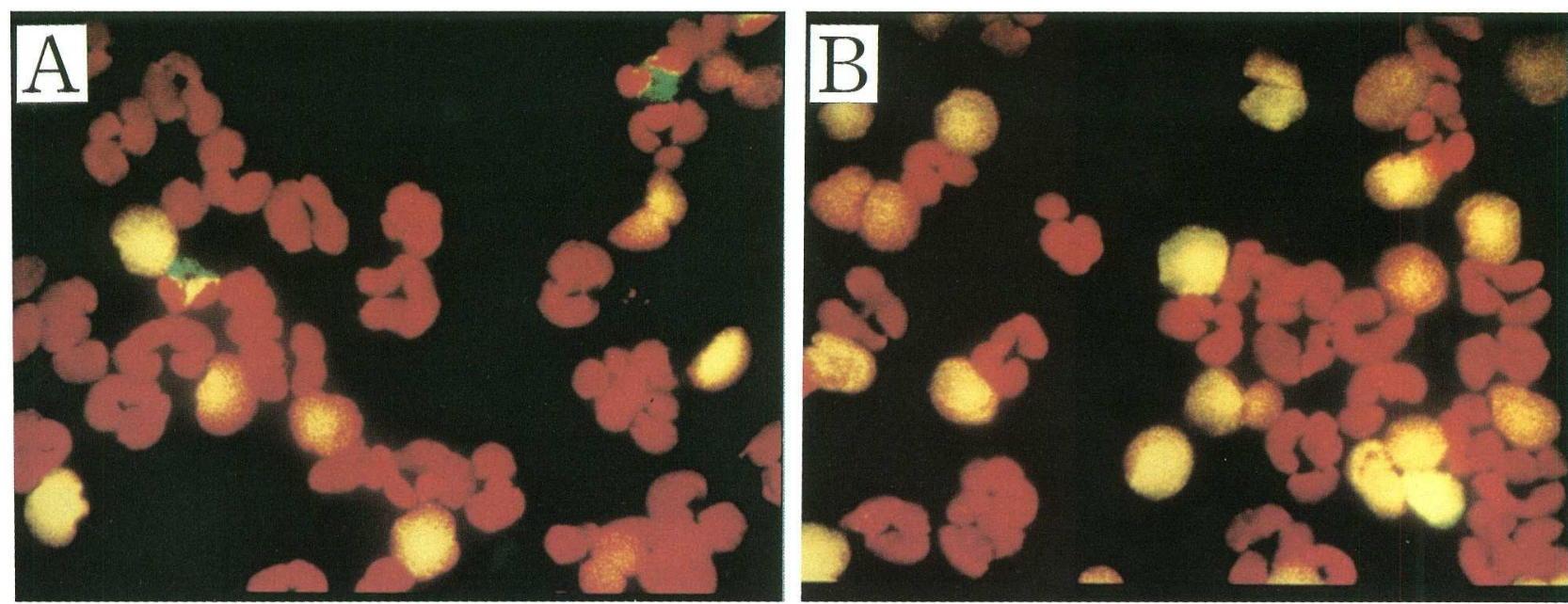

Figure 4. TUNEL stain of neutrophils cultured for 12 hours in control and liver cirrhosis. Neutrophils were observed by confocal laser microscopy $(\times 800)$. (A) control neutrophils, and $(B)$ neutrophils from cirrhotic patients. The number of TUNELpositive cells was markedly greater in cirrhotic patients than in controls.

improve with splenic embolization therapy (21) or splenectomy $(2,22)$. The role of hypersplenism in the neutropenia of cirrhosis remains controversial.

We demonstrated in cirrhotic patients, decreased neutrophil viability and neutrophil changes compatible with apoptosis, using the TUNEL method and assessing the DNA laddering at 180-200bp, a biochemical hallmark of apoptosis (23-28).

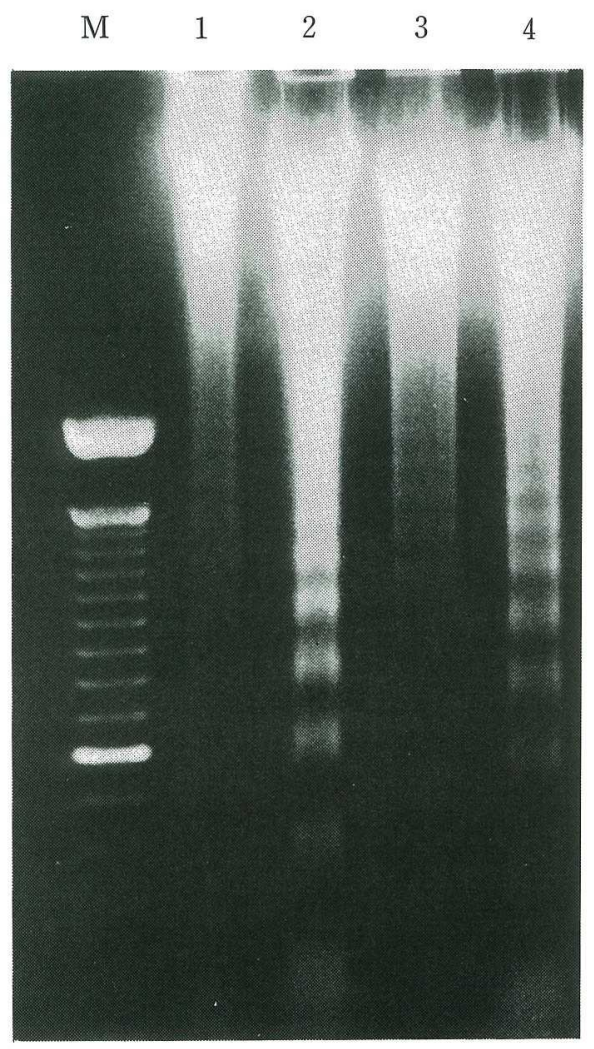

These findings suggest that neutrophils from cirrhotic patients have a shorter life span via apoptosis than do control neutrophils.

Mature human neutrophils undergo spontaneous apoptosis more rapidly, compared to hematocytes such as monocytes and eosinophils in vitro (29). Savill et al reported that apoptotic neutrophils are swiftly recognized and phagocytosed by macrophages $(12,30)$. A recent study on neutrophil kinetics in OK-432-treated rats indicated that apoptotic neutrophils were phagocytosed mainly by Kupffer cells or macrophages in the hepatic sinusoids, showing that the liver serves a major role in the clearance of apoptotic neutrophils (14). If accelerated neutrophil apoptosis can be observed in vivo, it may help explain the neutropenia in human cirrhosis, because the number of apoptotic neutrophils recognized and removed by phagocytes is increased. It has been reported that the neutropenia in patients with chronic splenomegaly may be caused either by increased destruction of granulocytes in the spleen or increased margination within the spleen (8). Hypersplenism may lead to rapid clearance of apoptotic neutrophils and this may partly explain the neutropenia in cirrhotic patients with splenomegaly. However, the neutropenia in cirrhotic patients is due not only to accelerated neutrophil apoptosis but also to other mechanisms. We should investigate granulopoiesis in cirrhotic patients and

Figure 5. Gel electrophoresis of DNA from cultured neutrophils. Total DNA was extracted (see Methods) and applied on a $1 \%$ agarose gel containing ethidium bromide. Lane $M$ is a standard 100base pair DNA ladder. Lanes 1 and 3 contain DNA from control neutrophils at 12 hours and 24 hours, respectively, and lanes 2 and 4 contain DNA from cirrhotic neutrophils at the same time points. The characteristic DNA ladder formation appeared at $\mathbf{1 2}$ hours more clearly in cirrhotic patients. 


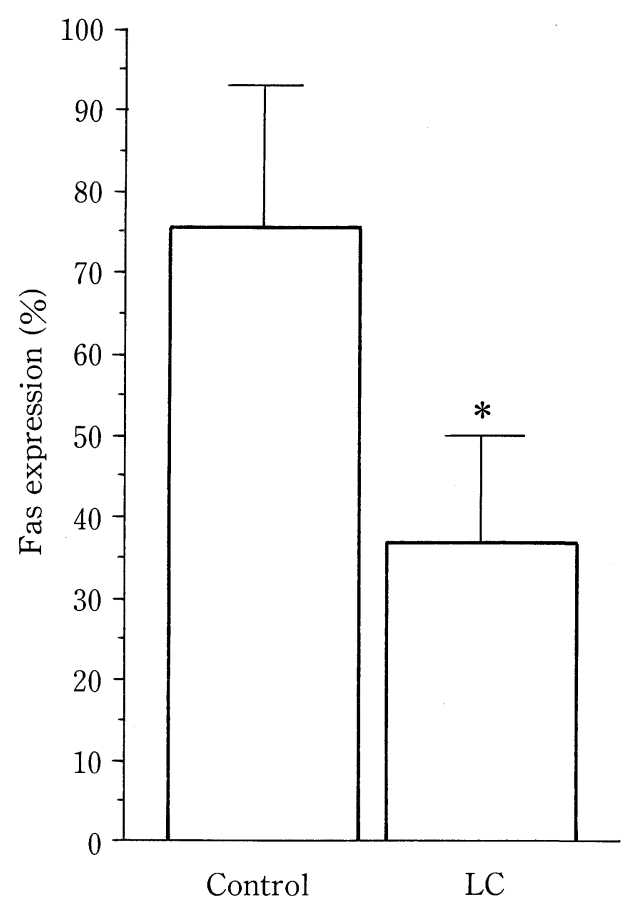

A whether or not many neutrophils in cirrhotic patients are distributed in marginal pools.

Several hypotheses regarding the mechanisms for accelerated apoptosis of neutrophils have been advocated. It has been demonstrated recently that the Fas/Fas ligand system may regulate neutrophil apoptosis $(29,31)$. The Fas antigen has been identified as the putative surface molecule capable of transducing apoptotic signals into cells (32). We speculated that neutrophils from cirrhotic patients may express Fas antigen more strongly than do control neutrophils. However, the expression of Fas antigen on neutrophils was unexpectedly reduced in the cirrhotic group. One reason for this may be that Fas antigen, as well as Fcy RIII, may have been shed from the surface of neutrophils during the course of apoptosis. Fc $\gamma$ RIII, a low affinity receptor for immunoglobulin $\mathrm{G}$, is also known to be shed by neutrophils during apoptosis $(33,34)$. The neutrophils progressively reduced their Fas expression with time during in vitro culture, in correlation with an increase of neutrophils exhibiting morphological apoptotic changes (data not shown). Another explanation for the decreased Fas antigen expression may be the adaptive down-regulation for chronic neutropenia in cirrhosis. Neutrophil apoptosis can be regulated by mechanisms other than the Fas pathway (29). Therefore, the reduced
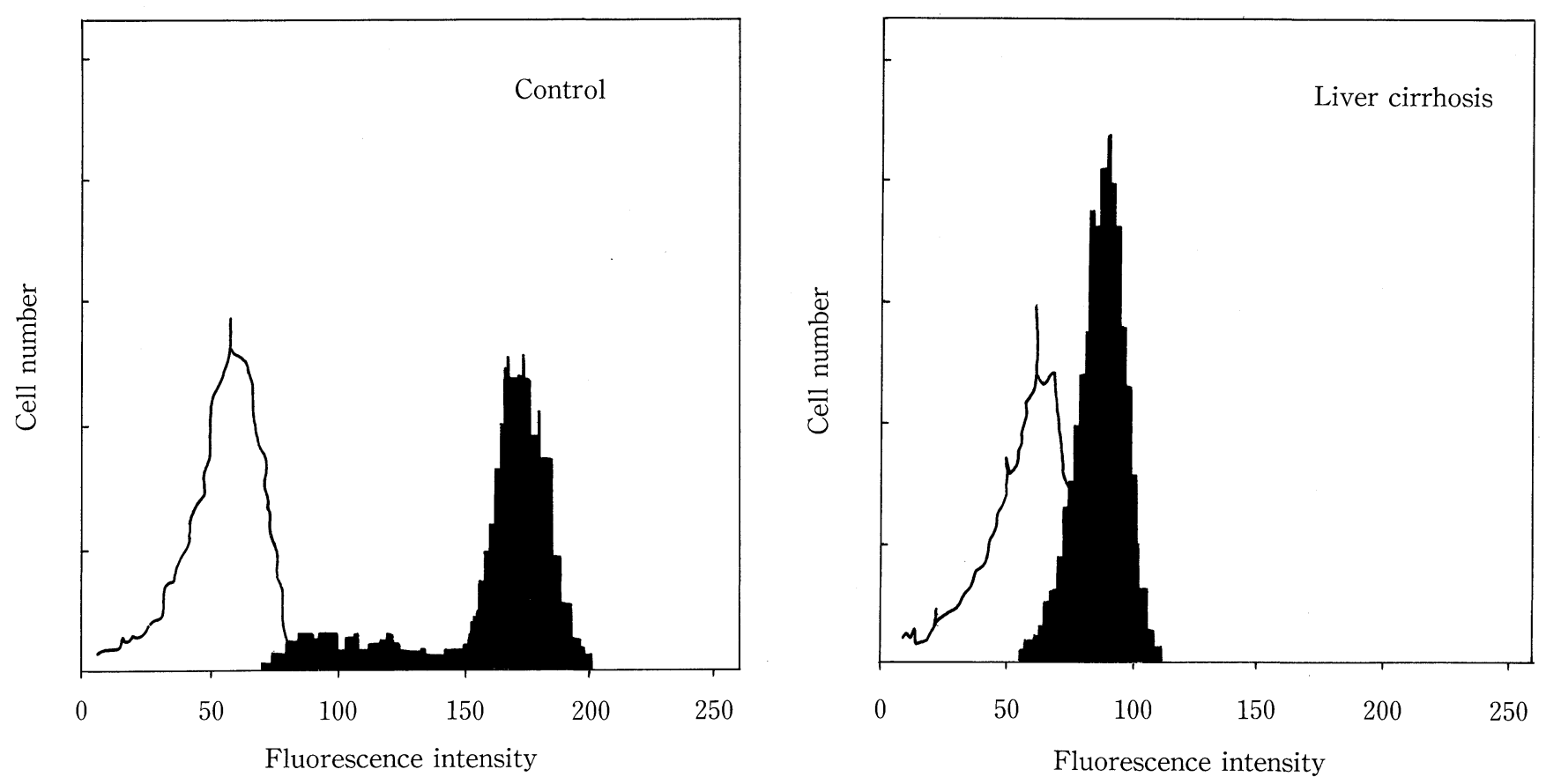

B

Figure 6. Fas antigen expression on freshly isolated neutrophils from control and cirrhotic patients. Neutrophils were stained with FITC-conjugated anti-Fas monoclonal antibody (mAb) and FITC-conjugated mouse IgG1 mAb and analyzed by flow cytometry. (A) Percent Fas expression on neutrophils was lower in liver cirrhosis $(n=15)$ than in controls $(n=10)$. Results represent mean $\pm \mathrm{SD} ;{ }^{*} \mathrm{p}=\mathbf{0 . 0 0 0 1}$, control $(\mathbf{7 5 . 7} \pm \mathbf{1 7 . 6 \%})$ versus liver cirrhosis $(39.6 \pm \mathbf{1 3 . 4 \%})$. Mean flow intensity values for control and liver cirrhosis were $120.5 \pm 31.7$ and $82.8 \pm 4.9$, respectively. (B) Representative histograms of flow cytometric analysis of neutrophils. The open curve represents neutrophils stained with control antibody and the solid histograms represent neutrophils stained with anti-Fas. Control neutrophils were comprized of a markedly greater population having high fluorescence intensity than in cirrhotic patients. 


\section{Neutrophil Apoptosis in Cirrhosis}

expression of Fas antigen on neutrophils from cirrhotic patients may show that neutrophil apoptosis is not merely mediated by Fas/Fas ligand system. Further study is required to clarify the mechanism of neutrophil apoptosis in liver cirrhosis.

In conclusion, the life span of the neutrophil in cirrhotic patients is shortened by accelerated apoptosis in vitro. This finding may help elucidate the neutropenia in cirrhosis and explain the increased rate of bacterial infections seen in this disease. This study may also provide new insight into neutrophil kinetics in cirrhotic patients.

Acknowledgements: We are grateful to Drs. Hirohisa Yano, Kohji Yoshimoto, and Yuriko Koga for their helpful discussion. We thank Miss Ritsuko Seki for her expert technical assistance.

\section{References}

1) Klipstein FA, Lindenbaum J. Folate deficiency in chronic liver disease. Blood 25: 443, 1965.

2) Ohashi T, Fujiwara K. Hematologic abnormalities in liver disease. Nippon Naika Gakkai Zasshi (J Jpn Soc Intern Med) 71: 1677, 1982 (in Japanese).

3) Smith JA, Lonergan ET, Sterling K. Spur-cell anemia: Hemolytic anemia with red cells resembling acanthocytes in alcoholic cirrhosis. N Engl J Med 271: 396, 1964.

4) Abrahamsen AF. Platelet survival studies in man. With special reference to thrombosis and atherosclerosis. Scand J Haematol Suppl 3: 1, 1968.

5) Aster RH. Pooling of platelets in the spleen. Role in the pathogenesis of "hypersplenic" thrombocytopenia. J Clin Invest 45: 645, 1966.

6) Sacchetti G, Boccacio P, Ponassi A, et al. Quantitation and distribution of neutrophilic granulocytes after splenectomy. Abstracts Xth Int Congr int Soc Haematol, Stockholm, 1964.

7) Reed IL, Barry P, Wong H, Greenberg MS. Granulocyte turnover in patients with cirrhosis. Clin Res 14: 325, 1966 (Abstract).

8) Uchida $T$, Kariyone $S$. Intravascular granulocyte kinetics and spleen size in patients with neutropenia and chronic splenomegaly. J Lab Clin Med 82: 9, 1973.

9) Ohki I, Dan K, Kuriya S, Nomura T. A study on the mechanism of anemia and leukopenia in liver cirrhosis. Jpn J Med 27: 155, 1988.

10) Cartwright GE, Athens JW, Wintrobe MM. The kinetics of granulopoiesis in normal man. Blood 24: 780, 1964.

11) Kerr JF, Wyllie AH, Currie AR. Apoptosis: a basic biological phenomenon with wide-ranging implications in tissue kinetics. Br J Cancer 26: 239, 1972.

12) Savill JS, Wyllie AH, Henson JE, Walport MJ, Henson PM, Haslett C. Macrophage phagocytosis of aging neutrophils in inflammation. Programmed cell death in the neutrophil leads to its recognition by macrophages. J Clin Invest 83: 865, 1989.

13) Grigg JM, Savill JS, Sarraf C, Haslett C, Silverman M. Neutrophil apoptosis and clearance from neonatal lungs. Lancet 338: 720, 1991.

14) Shi J, Fujieda H, Kokubo Y, Wake K. Apoptosis of neutrophils and their elimination by Kupffer cells in rat liver. Hepatology 24: 1256, 1996.

15) Haslett C, Guthrie LA, Kopanik MM, Johnston RB Jr, Henson PM. Modulation of multiple neutrophil functions by preparative methods or trace concentrations on bacterial lipopolysaccharide. Am J Pathol 119:
$101,1985$.

16) Gavrieli Y, Sherman Y, Ben-Sasson SA. Identification of programmed cell death in situ via specific labeling of nuclear DNA fragmentation. J Cell Biol 119: 493, 1992.

17) Wyllie AH, Kerr JF, Currie AR. Cell death: the significance of apoptosis. Int Rev Cytol 68: 251, 1980.

18) Payne CM, Glasser L, Tischler ME, et al. Programmed cell death of the normal human neutrophil: an in vitro model of senescence. Microsc Res Tech 28: 327, 1994.

19) Wyke RJ. Problems of bacterial infection in patients with liver disease. Gut 28: 623, 1987.

20) Yoshida H, Hamada $T$, Inuzuka S, Ueno $T$, Sata M, Tanikawa K. Bacterial infection in cirrhosis, with and without hepatocellular carcinoma. Am J Gastroenterol 88: 2067, 1993.

21) Spigos DG, Jonasson O, Mozes M, Capek V. Partial Splenic Embolization in the Treatment of Hypersplenism. AJR Am J Roentgenol 132: 777, 1979.

22) Chisholm M. Haematological disorders in liver disease. In: Liver and biliary disease, Wright R, Alberti KGMM, Karran S, Millward-Sadler GH, Eds. WB Saunders Company Ltd, London, Philadelphia and Toronto, 1979, p. 159.

23) Wyllie AH. Glucocorticoid-induced thymocyte apoptosis is associated with endogenous endonuclease activation. Nature (Lond.) 284: 555, 1980.

24) Wyllie AH, Morris RE. Hormonal induced cell death: purification and properties of thymocytes undergoing apoptosis after glucocorticoid treatment. Am J Pathol 109: 78, 1985.

25) Russel JH. Internal disintegration model of cytotoxic lymphocyte-induced target damage. Immunol Rev 72: 97, 1983.

26) Cohen JJ, Duke RC. Glucocorticoid activation of a calcium dependent endonuclease in thymocyte nuclei leads to cell death. J Immunol 132: 38, 1984.

27) Wyllie AH, Morris RG, Smith AL, Dunlop D. Chromatin cleavage in apoptosis: association with condensed chromatin morphology and dependence on macromolecular synthesis. J Pathol 142: 67, 1984.

28) Ucker DS. Cytotoxic T lymphocytes and glucocorticoids activate an endogenous suicide process in target cells. Nature (Lond.) 327: 62, 1987.

29) Liles WC, Kiener PA, Ledbetter JA, Aruffo A, Klebanoff SJ. Differential expression of Fas (CD95) and Fas ligand on normal human phagocytes: implications for the regulation of apoptosis in neutrophils. J Exp Med 184: 429, 1996.

30) Savill J, Dransfield I, Hogg N, Haslett C. Vitronectin receptor-mediated phagocytosis of cells undergoing apoptosis. Nature (Lond.) 343: 170, 1990.

31) Iwai K, Miyawaki T, Takizawa T, et al. Differential expression of bcl-2 and susceptibility to anti-Fas-mediated cell death in peripheral blood lymphocytes, monocytes, and neutrophils. Blood 84: 1201, 1994.

32) Itoh $\mathrm{N}$, Yonehara $\mathrm{S}$, Ishii $\mathrm{A}$, et al. The polypeptide encoded by the cDNA for human cell surface antigen Fas can mediate apoptosis. Cell 66: 233, 1991.

33) Dransfield I, Buckle AM, Savill JS, McDowall A, Haslett C, Hogg N. Neutrophil apoptosis is associated with a reduction in CD16 (Fc $\gamma$ RIII) expression. J Immunol 153: 1254, 1994.

34) Homburg $\mathrm{CH}$, de Hass $\mathrm{M}$, von dem Borne AE, Verhoeven AJ, Reutelingsperger CP, Roos D. Human neutrophils lose their surface Fcy RIII and acquire Annexin $\mathrm{V}$ binding sites during apoptosis in vitro. Blood 85: 532, 1995. 